\title{
New women-specific diagnostic modules: the Composite International Diagnostic Interview for Women (CIDI-VENUS)
}

\author{
Julia Martini \& Hans-Ulrich Wittchen \& Claudio N. Soares \& Amber Rieder \& Meir Steiner
}

\begin{abstract}
The World Health Organization-Composite International Diagnostic Interview (WHO-CIDI) is a highly structured interview for the assessment of mental disorders, based on the definitions and criteria of the fourth edition of the American Psychiatric Association's Diagnostic and Statistical Manual of Mental Disorders (DSM-IV). Over the past decade it has become evident that the CIDI does not sufficiently address the assessment needs of women. Women are affected by most mental disorders, particularly mood and anxiety disorders, approximately twice as frequently as men. Women-specific disorders, such as Premenstrual Syndrome (PMS), Premenstrual Dysphoric Disorder (PMDD), psychiatric disorders during pregnancy and postpartum as well as during the perimenopause, menopause and beyond are not addressed by the standard CIDI diagnostic modules. In addition, the CIDI in its current form does not address the potential effect that female reproductive milestones may have on diagnosis, treatment and prevention of mental disorders in women. Our aim was to develop a new women specific platform (CIDI-VENUS; CIDI-V) to be embedded in the existing CIDI that will address the above mentioned current deficiencies. Guided by a team of experts in the field of Women's Mental Health from Canada and Germany the following modules were developed: 1) A complete menstrual history and comprehensive contraceptive history with a link to the Premenstrual Symptoms Screening Tool (PSST). 2) A complete perinatal history of pregnancies, miscarriages, terminations, still births, death of a child, with details of current pregnancy including gestation and expected date of confinement, labour history and breastfeeding, history of tobacco, alcohol, and other substance use including prescription drugs during pregnancy and postpartum, a section on specific phobias and on recurrent obsessive/ compulsive thoughts/behaviours (OCD) related to the baby with a link to the Perinatal Obsessive-Compulsive Scale (POCS), as well as a link to the Edinburgh Postnatal Depression Scale (EPDS). 3). A detailed history of use of hormone therapy (e.g. pills, patches, implants, etc.) with a focus on (peri-) menopausal women, differentiating between physical and psychological symptoms with a link to the Menopause Visual Analogue Scales (M-VAS) and to the Greene Climacteric Scale. 4) An iterative module concluding each CIDI section to specify the course of mental disorders during the reproductive stages and menopausal transition. While retaining core diagnostic sections and diagnostic algorithms, the CIDI-V is enriched by women-specific diagnostic modules, providing a wealth of clinically relevant information about women's mental health, not available anywhere else in our current psychiatric diagnostic instruments.
\end{abstract}

Keywords: Composite international diagnostic interview, CIDI-VENUS, Menstrual cycle, Pregnancy, Postpartum, Menopausal transition 


\section{Introduction: standardized diagnostic interviews for the assessment of mental disorders}

Several diagnostic instruments exist for the assessment of mental disorders in clinical and epidemiological research. These include the Structured Clinical Interview for DSMIII- R (SCID) (Spitzer et al. 1992; Williams et al. 1992), the MINI International Neuropsychiatric Interview (M.I.N.I.) (Sheehan et al. 1998); the Schedule for Affective Disorders and Schizophrenia (SADS) (Endicott and Spitzer 1978), the Schedules for Clinical Assessment in Neuropsychiatry (SCAN) (van Gülick-Bailer et al. 1995), the Diagnostic Interview Schedule (DIS) (Robins et al. 1981), the Present State Examination (PSE) (Wing et al. 1974) and the Composite International Diagnostic Interview (CIDI) (Wittchen et al. 2001). The most frequently used tool in clinical and community epidemiological studies worldwide is the World Health Organization-Composite International Diagnostic Interview (WHO-CIDI) (Robins et al. 1988; Wittchen et al. 1991; Wittchen 1994; Kessler and Üstün 2004). Based on its predecessor, the DIS, for DSM-III and DSM-III-R (APA 1980, 1987), the CIDI was the product of a close collaboration with the authors of the PSE, within the context of WHO/ADAMHA Task Force on Diagnostic Classification and Instruments (Lépine et al. 1993; Semler et al. 1987; Wittchen and Nelson 1996). An attempt was made at the time, to cover within one instrument the definitions, criteria and diagnostic algorithms of both the ICD-10 (WHO 1993, Diagnostic Criteria for Research) and the DSM-IV (APA 2000). Since then several versions, modifications and variants of the CIDI have been developed for use in small and large scale epidemiological and clinical studies for lifetime, 12-month and crosssectional diagnoses; additionally interval and change- versions for longitudinal research became available, supplemented by various additional diagnostic modules (Andrews and Wittchen 1995; Cottler et al. 1991; Kessler and Üstün 2004; Kessler et al. 1998a, b, 2000; Lachner and Wittchen 1996; Lieb et al. 2000; Rubio-Stipec et al. 1993; Wittchen et al. 1995, 1998, 1996; Wittchen and Pfister 2004; overview see Wittchen et al. 2001). It is important to note that the diagnostic algorithms were retained in all versions, thus allowing for cross-walks from earlier to later versions even when changes in the diagnostic system occurred. Divided into 16 diagnostic sections, the CIDI allows the fully standardized symptom and syndrome assessment of a total of 56 core diagnoses of mental disorders including information regarding onset, recency, severity, and impairment as well as patterns of co-morbidity. It offers also some crude information about help seeking and health care utilization, and provides data about the temporal relationships of syndromes by incorporation of symptom and time-related questions for persistence and duration. Symptom questions address problems that the respondent has experienced, probing additionally for significance and causation (i.e. substance induced/ or due to general medical conditions) as well as for symptoms that have occurred in the person's lifetime or in other time-frames (e.g., past 12 months). Diagnoses of mental disorders can be obtained for the corresponding time-frames (current: 2 or 4 weeks, 12 months, lifetime) by the use of computerized algorithms (Essau and Wittchen 1993). The CIDI is a standardized diagnostic interview. The interviewer is instructed to ask all questions exactly as written, to code the respective answer of the respondent (interviewers are not allowed in the interview to code clinical impression, except for supplementary observational items), and to follow the fixed skip rules to enhance efficiency. All interview questions must be read exactly as written and the interviewer should not rephrase the question (Kessler and Üstün 2004; Wittchen and Semler 1990). The administration is further facilitated by the use of a Respondent Booklet, providing a visual presentation of more complex response options, symptom lists, and dimensional questionnaires. The CIDI can be administered by nonclinicians given appropriate standard training. Learning the CIDI requires a training seminar of several days up to one week duration for the paper and pencil administration and 2 to 3 
days for the Computer Assisted Personal Interview (CAPI) version. The CIDI is applicable for the age groups of 14 to 65 years and for respondents from different cultural and educational background (Robins et al. 1988). Respondents with severe intellectual disturbances, dementia or acute psychotic states should be excluded on the basis of the optional CIDI Mini- Mental Examination module (Wittchen and Pfister 1997).

In summary, the CIDI is easy to administer, available in several languages and has established reliability and validity (Andrews and Peters 1998; Essau and Wittchen 1993; Kessler et al. 1998a, b; Knappe et al. 2008; Lachner et al. 1988; Reed et al. 1998; Spengler and Wittchen 1988; Wittchen et al. 1989, 1996, 1998, 1999).

\section{The need for a female-specific diagnostic interview}

Over the past decade it became increasingly evident, that neither the CIDI nor other standard diagnostic interviews provide sufficiently detailed information about female-specific disorders, such as PMDD, female-specific characteristics of psychopathological presentations such as mental disorders with post-partum onset, the relationship of characteristics of the menstrual cycle with psychopathology and peri- and post menopausal manifestations of syndromes (Soares and Zitek 2008; Steiner et al. 2003a; Yonkers and McCunn 2007). Given the increased psychopathological burden for women associated with most diagnoses (Andrade et al. 2003), the lack of such an instrument has also impeded the accumulation of better clinical-epidemiological information regarding the core factors associated with the increased incidence and prevalence of mental disorders in women. Epidemiological studies consistently show that with the onset of the reproductive years at menarche, mood disorders are at least twice as common in women than in men (Kessler 2003; Lewinsohn et al. 1998; Steiner et al. 2003a; Wittchen and Jacobi 2005). A similar gender-specific pattern is also evident in anxiety, eating and somatoform disorders as well as with regard to the type and extent of comorbid patterns (Escobar et al. 1989; Fairburn and Harrison 2003; Rief et al. 2001; Wittchen and Jacobi 2005; Yonkers and McCunn 2007). There is also considerable evidence that onset, course, and prognosis of these disorders may be different for men and women (Fehm et al. 2005; Wittchen and Jacobi 2005). Due to the fact that almost all epidemiological instruments do not address the specific characteristics of women's reproductive years, it has been difficult to relate psychopathological syndromes and their course to core female-specific issues, such as the menstrual cycle, pregnancy, postpartum, and menopause (Steiner et al. 2003a; Yonkers and McCunn 2007). Additionally, some disorders that are exclusively relevant to women such as PMDD and Perinatal and Perimenopausal Disorders are not covered by the existent standard diagnostic tools. Despite the wide range of instruments available that specifically address some of these critical issues, these tools are typically questionnaires covering only a few domains and can not easily be embedded into one coherent and conceptually sound assessment instrument. Thus, except for some recent attempts to supplement the standard CIDI with female-specific diagnostic categories such as PMDD (Wittchen et al. 2002), so far-and to our knowledge - there is no instrument covering a broader spectrum of women-specific mental disorders.

\section{Designing a female-specific diagnostic interview}

In response to this marked deficit, the authors convened a working group to explore existing instruments and their suitability for developing a female-specific diagnostic assessment tool. The group decided, after careful review of existing evidence, on the following principles: 
1. The instrument should be a modification of an existing instrument, rather than a new standalone instrument. This should allow for easy comparison of any newly generated female specific data with existing data bases.

2. In-depth psychometric analyses should be performed on all newly-added as well as modified modules and sections.

3. The standardized interview approach should be maintained to increase inter-rater reliability and to ensure consistency between different research groups and different settings.

4. A lifetime interview approach in addition to cross-sectional data should be used to ensure lifetime information about the reproductive cycle. The interview should have established reliability and validity with regard to lifetime retrospective information as well as age of onset.

5. The utility of the instrument would profit substantially from incorporating dimensional aspects (Regier 2007; Shear et al. 2007).

6. The interview should be available in a computerized format (CAPI and diagnostic analysis) to avoid costly separate data entry and analysis.

7. Pilot data demonstrating the feasibility of incorporating female-specific questions and modules should be available from at least one clinical setting (see Steiner et al. 2008; Rieder et al. 2009).

Based on these considerations the group chose the CIDI platform as the most appropriate, promising and comprehensive interview available in meeting these requirements. This decision was further supported by a number of additional advantages, such as (a) the CIDI is modular and flexible allowing easy incorporation of diagnostic and syndromes modules as well as questionnaires, (b) the availability of existing training programs and (c) the relative ease of reliable administration and analysis. We acknowledged though the well known limitations of a non-clinician interview, ie lack of more subtle psychopathological differentiations a clinician might be able to code, clinical features and clinical severity ratings. Based on these considerations, a series of supplementary additions was designed, incorporated into the existing CIDI, and pilot-tested without changing the established skip rules, diagnostic modules, and algorithms of the CIDI (Steiner et al. 2008).

The content of the CIDI-VENUS (CIDI-V, Martini et al. 2007a, b; Steiner et al. 2007a, b)

Table 1 describes the structure of the standard WHO-CIDI, detailing in which sections what type of modular extensions were incorporated.

\section{Section A}

The rather brief introductory Section (Section A, Demographics) of the CIDI, which originally only included crude biosocial and socio-demographic information, was supplemented by a series of new questions providing a wide range of female-specific general health information, that cuts across all diagnostic categories. This expansion also links initial answers to subsequent questions in the interview. For example, if the stem questions for menopause are denied, respective questions are skipped later on in the interview (and 
respectively suppressed in the computerized version). This section also includes a standardized assessment of the respondents' menstrual cycle, pregnancy, postpartum period, peri- and postmenopause as well as a detailed obstetric and gynaecologic history. The questions are partly supported by respondent lists and questionnaires as part of the Respondent Booklet (Martini et al. 2007b; Steiner et al. 2007b).

\section{Iterative Modules to relate symptoms and disorders to reproductive stages and menopausal transition in diagnostic sections}

Based on this background information collected in Section A, the subsequent diagnostic sections are supplemented by an Iterative Module (see Table 2) to assess the temporal association of previously reported symptoms and disorders in each respective Section with regard to menstrual cycle, pregnancy, postpartum period, peri- and postmenopause. These additional questions at the end of the diagnostic Section allow the determination of how onset, course and symptom pattern of the respective syndrome is related to women-specific issues. In the mood, anxiety, eating, somatoform and psychotic disorders sections (psychopathological syndromes sections) the instrument asks specifically about the associated symptoms and their impact (e.g., improvement or worsening, increase or decrease of frequency or symptom magnitude) during the different phases of the menstrual cycle and during pregnancy, postpartum, and menopausal transition. For substance use disorders (use of nicotine, alcohol, drugs) and use of medications (substance use sections) the possible teratogenic effects on the offspring were considered in relation to pregnancy and postpartum, assessing whether the respondent stopped, reduced or continued substance use during pregnancy and breastfeeding (see Table 2).

The Section for Depressive Disorders allows for differentiation of the subtypes of major depression including specification of severity (e.g. severe episode with psychotic features).

The Section for Specific Phobias was expanded by questions regarding the strong fear (or avoidance) of pregnancy and delivery. Fertile women who prevent a pregnancy despite of the desire to have a child were asked about excessive avoidance strategies (e.g., usage of several contraception methods), whereas for pregnant women, requested anaesthesia or elective caesarean section were considered to be relevant.

The Section of Posttraumatic Stress Disorder is extended by a set of questions concerning the occurrence of potentially traumatic events during pregnancy, associated complications during gestation or childbirth, and experience of childbirth (incl. subsequent psychopathological symptoms). For Eating Disorders additional questions concerning weight gain or weight reduction in connection with pregnancy (incl. Hyperemesis Gavidarum), postpartum, and menopause were added (see Table 1).

\section{Probe flow chart and time-related questions}

The inclusion of women-specific issues also made it necessary to amend some of the CIDIspecific probe questions that are used for specific symptoms and syndromes to exclude substance-related and somatic-related factors (Essau and Wittchen 1993; Rubio-Stipec et al. 1993). Here the instrument allows for an additional specification for serious symptoms which are mainly attributed to menstrual cycle, pregnancy, postpartum, or menopause as a specific variant of a 'somatic condition'. 
The analysis of a temporal coincidence of psychological symptoms and women-specific issues further required the expansion of the CIDI time-related questions (Essau and Wittchen 1993), allowing now for coding the exact time a particular symptom occurred.

\section{Modifications of the Respondent Booklet (Martini et al. 2007b; Steiner et al. 2007b)}

The supplementary questions and modules also prompted the need for a considerable expansion of the Respondent Booklet and the incorporation of dimensional scales established in previous research. In particular we added:

- The Born-Steiner Irritability Scale (B-SIS), (Born et al. 2008) which is a self-rating scale to assess irritability, a prominent symptom in the spectrum of female-specific mood disorders (Born and Steiner 2000).

- The Premenstrual Symptoms Screening Tool (PSST), (Steiner et al. 2003b) which was developed on the basis of DSM-IV research criteria for the Premenstrual Dysphoric Disorder (APA 2000) and reflects these criteria with additional severity ratings.

- The Edinburgh Postnatal Depression Scale (EPDS) (Cox et al. 1987) as a short, reliable, valid and widely and internationally accepted screening questionnaire to assess depression and anxiety during pregnancy and the postpartum period.

- The Greene Climacteric Scale (Greene 1998) as a reliable and valid questionnaire, which measures psychological, somatic, and vasomotor menopausal symptoms.

- The Perinatal Obsessive-Compulsive Scale (POCS) (Lord et al. 2008)

- The Menopause Visual Analogue Scales (M-VAS) (Steiner et al. 2008) (see Table 1).

\section{Diagnostic analysis and output}

Maintaining the integrity of the overall computerized algorithmic platform for the standard sections of the CIDI, we expanded the CIDI output that typically only reveals categorical diagnostic information (for threshold and subthreshold disorders, core syndromes and information about onset, subtype and recency) (Wittchen 1993).

The CIDI-Venus standard output (see Fig. 1) was supplemented by:

- women-specific information regarding the individual gynaecological history (e.g., menarche, abdominal operations, and hormonal therapy), - adverse pregnancy outcomes (number and dates of abortions, miscarriages, stillbirths, or sudden infant death), - number of children and information concerning birth outcomes (e.g., gestational age, birth weight and length, duration of childbirth),

- the PSST and the corresponding decision rules (Steiner et al. 2003b) as well as scoring of the EPDS, the Greene Climacteric Scale, the M-VAS, and the POCS (Cox et al. 1987; Greene 1998; Lord et al. 2008)

The output for each diagnosis shows whether the respondent attributes the beginning or an aggravation of the reported psychopathological syndromes to women-specific issues (menstrual cycle, pregnancy, postpartum, or menopause). It also provides information about termination or reduction in substance use during pregnancy and while breastfeeding.

\section{Conclusion and outlook}

The standardized question format of the CIDI-V provides a systematic and comprehensive approach to current female-specific core questions in mental disorders and 
psychopathological research, allowing a reliable examination of a wide range of mental disorders with embedded modular additions of women-specific conditions and factors (menstruation, pregnancy, postpartum, or menopause). The availability of a standardized and comprehensive categorical and dimensional examination of mental disorders and psychopathological syndromes during pregnancy as well as pregnancy and delivery outcomes (e.g., gestational age, mode of delivery) is expected to provide an extensive and solidly coordinated basis for cross-sectional and longitudinal studies in epidemiological and clinical settings. Linked to the already existent family-genetic CIDI version (Lieb et al. 2000) the instrument might also enhance the efficiency and the detail of studies dealing with the familial transmission of mental disorders as well as perinatal research in general.

The development of a male-specific CIDI supplement might be a future challenge, aiming a more detailed examination of gender-differences as well as an investigation of conditions that are more common in men (e.g. ADHD, autism spectrum disorders) (van Engeland and Buitelaar 2008; Wittchen and Jacobi 2005).

The CIDI-V was primarily developed for epidemiological studies to examine women-specific disorders, but it can also be used for clinical practice. Particularities concerning occurrence (prevalence and incidence), maintenance, comorbidity patterns, and temporal relationships with the female reproductive cycle may be explored on this basis more comprehensively. The CIDI-V utility is enhanced by further covering critical issues like the impact of adverse pregnancy outcomes (e.g. stillbirth) and consequences of abdominal operations.

The CIDI-V is available as lifetime and 12-month cross-sectional CAPI as well as paper and pencil version in English (Steiner et al. 2007a, b) and German (Martini et al. 2007a, b). The psychometric exploration of CIDI-V is currently underway; however one would expect that the reliability and validity of diagnostic sections and embedded instruments will not differ significantly from those in previous studies, given that only some of the context variables are different.

Table 1: Sections of the standard WHO-CIDI and women-specific supplements of the CIDI-V (Wittchen and Pfister 1997; Martini et al. 200a,b; Steiner et al. 200a,b)

\begin{tabular}{lll} 
WHO-CIDI & \multicolumn{1}{c}{ Supplements: CIDI-V Interview } & \multicolumn{1}{c}{$\begin{array}{l}\text { Supplements: CIDI-V } \\
\text { Respondent Booklet }\end{array}$} \\
\hline A Demographics & $\begin{array}{l}\text { Reproductive history: current pregnancy } \\
\text { (expected date of delivery, first day of last }\end{array}$ & - PSST (Steiner et al. \\
& menstrual period); multiple pregnancy; live births & - M-VAS (Steiner et al. \\
& (gestational age at birth, birth weight, mode of & 2008) \\
& delivery, breastfeeding history); adverse & - Greene Climacteric Scale \\
& pregnancy outcomes (miscarriages, abortion, & (Greene 1998) \\
& stillbirth, sudden infant death) & - List V0: Abdominal \\
& Menstrual history: premenstrual symptoms; & operation \\
& regularity and duration of a cycle & - List V1: Indication for \\
& Obstetric and gynaecologic history: operations; & abdominal operation \\
& contraceptive history & - List V2: Contraception \\
& Menopausal history: symptoms and causes (e.g., & methods \\
& surgically induced) of menopause; hormone & - List V3: Cause of \\
& therapy & amenorrhoea \\
& - List V4: Menopausal \\
\hline
\end{tabular}




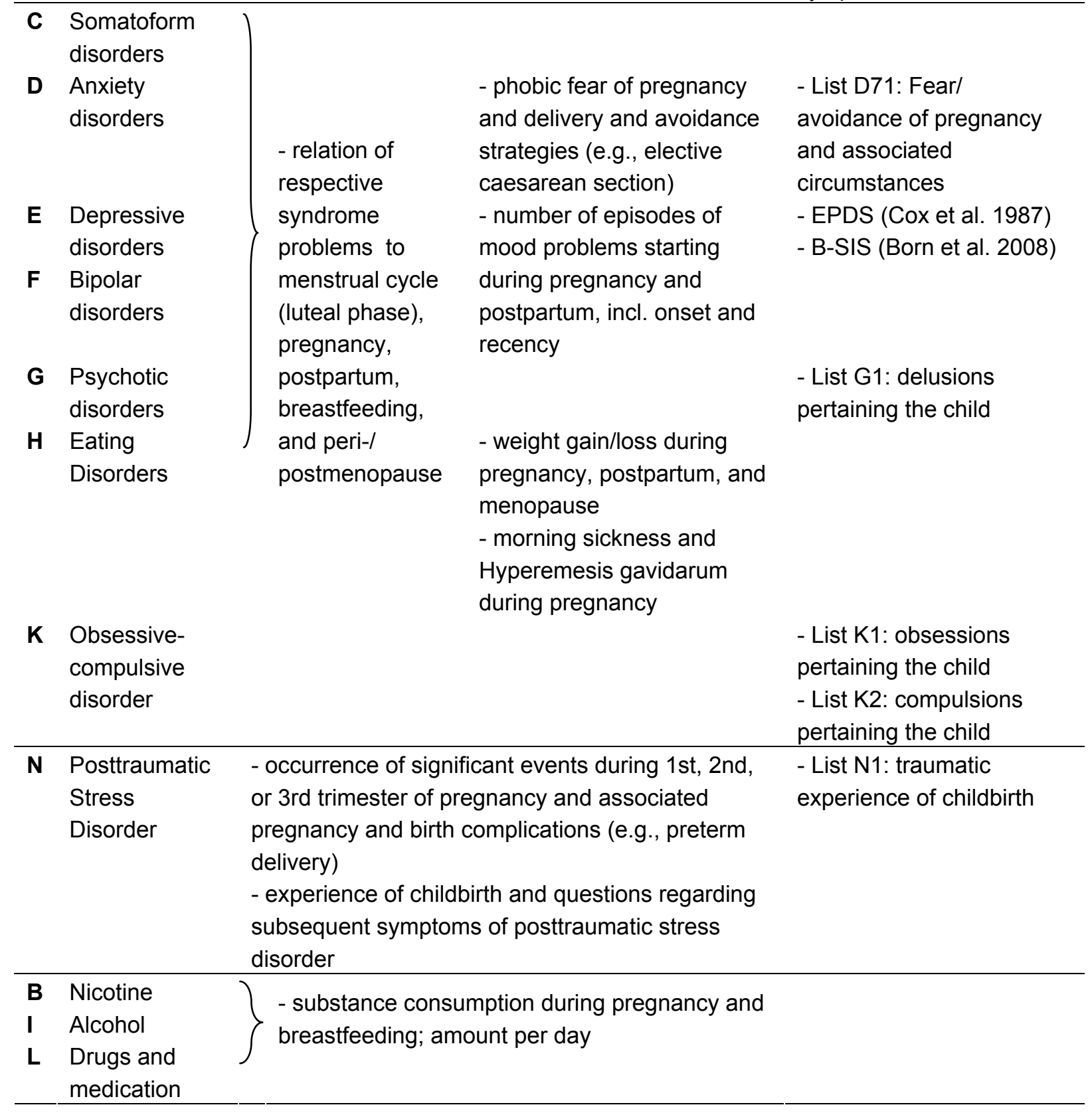

Table 2: Example for Questions of the Iterative Module in Psychopathological syndromes sections and substance use sections

\begin{tabular}{|c|c|}
\hline \multicolumn{2}{|c|}{ Iterative Module: Psychopathologic syndromes section } \\
\hline Menstrual Cycle & $\begin{array}{l}\text { Were any of these (respective syndrome problems) related to your menstrual } \\
\text { cycle? Did they get worse before [1], during [2] or after [3] your menstruation } \\
\text { [code lowest number]? If yes, specify and code, which. }\end{array}$ \\
\hline \multirow[t]{4}{*}{ Pregnancy } & Did any of these (respective syndrome problems) start while you were pregnant? \\
\hline & If yes, specify and code which. \\
\hline & Did any of these (respective syndrome problems) change during pregnancy? \\
\hline & $\begin{array}{l}\text { Overall, while you were pregnant, would you say that these (respective syndrome } \\
\text { problems) got better [1], worse [3] or remain unchanged [2]? }\end{array}$ \\
\hline Postpartum/ & Did any of these (respective syndrome problems) start in the year after having a \\
\hline
\end{tabular}


baby? If yes, specify and code which.

Did any of these (respective syndrome problems) change in the year after having a baby? Overall, in the year after having a baby, would you say that these (respective syndrome problems) got better [1], worse [3] or remain unchanged [2]?

Did any of these (respective syndrome problems) start while you were breastfeeding? If yes, specify and code which.

Did any of these (respective syndrome problems) change while you were breastfeeding? Overall, while you were breastfeeding, would you say that these (respective syndrome problems) got better [1], worse [3] or remain unchanged [2]?

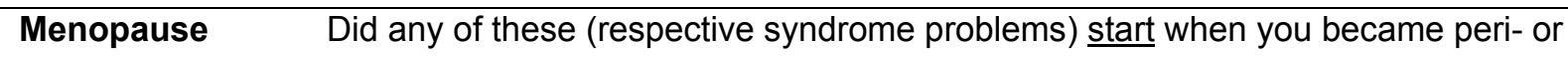
postmenopausal? If yes, specify and code, which.

Did any of these (respective syndrome problems) change when you became perior postmenopausal? Overall, when you became peri- or postmenopausal, would you say that these (respective syndrome problems) got better [1], worse [3] or remain unchanged [2]?

Iterative Module: Substance Use Sections

Pregnancy Did you (use substance $X$ ) when you learned that you are pregnant? Did you completely stop/ reduce (using substance $X$ ) when you learned that you are pregnant? Code type and amount per day.

Breastfeeding Did you (use substance $X$ ) when you were breastfeeding? Did you completely stop/ reduce (using substance $\mathrm{X}$ ) when you were breastfeeding? Code type and amount per day.

Note, questions were partly adapted to the content of the respective section (e.g., asking for severity or frequency instead of or additionally to worsening)

\section{Acknowledgments}

The authors would like to thank team members of the Women's Health Concerns Clinic, St. Joseph's Healthcare, Hamilton, Ontario, Canada who participated in the development and language editing of the CIDI-V, in particular Leslie Born, as well as Jens Siegert and Christian Soltau (Institute of Clinical Psychology and Psychotherapy, Technische Universität Dresden, Germany) for their expert input into the design of the CIDI and the structured programming of the CIDI-V CAPI Version.

\section{References}

- American Psychiatric Association (APA) (1980) Diagnostic and statistical manual of mental disorders, 3rd edn. DSM-III. American Psychiatric Association, Washington DC

- American Psychiatric Association (APA) (1987) Diagnostic and statistical manual of mental disorders, 3rd rev. edn. DSM-III-R. American Psychiatric Association, Washington DC 
- American Psychiatric Association (APA) (2000) Diagnostic and statistical manual of mental disorders, 4th edn. text revision. DSM-IV-TR. American Psychiatric Association, Washington DC

- Andrade L, Caraveo-Anduaga JJ, Berglund PA, Bijl RV, de Graaf R, Vollebergh WAM, Dragomirecka E, Kohn R, Keller M, Kessler RC, Kawakami N, Kilic C, Offord D, Ustun TB, Wittchen H-U (2003) The epidemiology of major depressive episodes: results from the International Consortium of Psychiatric Epidemiology (ICPE) surveys. Int J Methods Psychiatr Res 12:3-21

- Andrews G, Peters L (1998) The psychometric properties of the composite international diagnostic interview. Soc Psychiatry Psychiatr Epidemiol 33:80-88

- Andrews G, Wittchen H-U (1995) Clinical practice, measurement and information technology. Psychol Med 25:443-446

- Born L, Steiner M (2000) Irritability: the forgotten dimension of female-specific mood disorders. Arch Womens Ment Health 2:153-167

- Born L, Koren G, Lin E, Steiner M (2008) A new, female-specific irritability rating scale. J Psychiatry Neurosci 33:344-354

- Cottler L, Robins LN, Grant B, Blaine J, Towle I, Wittchen H-U, Sortorius N (1991) The CIDI-core substance abuse and dependence questions: cross cultural and nosological issues. Br J Psychiatry 159:653-658

- Cox JL, Holden JM, Sagovsky R (1987) Detection of postnatal depression: development of the 10-item Edinburgh postnatal depression scale. Br J Psychiatry 150:782-786

- Endicott J, Spitzer RL (1978) A diagnostic interview: the schedule for affective disorders and Schizophrenia. Arch Gen Psychiatry 35:837-844

- Escobar JI, Rubiostipec M, Canino G, Karno M (1989) Somatic Symptom Index (SSI) — New and abridged somatization construct — Prevalence and epidemiological correlates in 2 large community samples. J Nerv Ment Dis 177:140-146

- Essau CA, Wittchen H-U (1993) An overview of the Composite International Diagnostic Interview (CIDI). Int J Methods Psychiatr Res 3:79-85

- Fairburn CG, Harrison PJ (2003) Eating disorders. Lancet 361:407-416

- Fehm L, Pelissolo A, Furmark T, Wittchen H-U (2005) Size and burden of social phobia in Europe. Eur Neuropsychopharmacol 15:453-462

- Greene JG (1998) Constructing a standard climacteric scale. Maturitas 29:25-31

- Kessler RC (2003) Epidemiology of women and depression. J Affect Disord 74:5-13

- Kessler RC, Üstün TB (2004) The World Mental Health (WMH) Survey Initiative Version of the World Health Organziation (WHO) Composite International Diagnostic Interview (CIDI). Int J Methods Psychiatr Res 13:93-121

- Kessler RC, Andrews G, Mroczek D, Üstün B, Wittchen H-U (1998a) The world health organization Composite International Diagnostic Interview Short-Form (CIDISF). Int J Methods Psychiatr Res 7:171-185

- Kessler RC, Wittchen H-U, Abelson JM, McGonagle K, Schwarz N, Kendler KS, Knäuper B, Zhao S (1998b) Methodological studies of the Composite International Diagnostic Interview (CIDI) in the US National Comorbidity Survey (NCS). Int J Methods Psychiatr Res 7:33-55

- Kessler RC, Wittchen H-U, Abelson J, Zhao S (2000) Methodological issues in assessing psychiatric disorders with self-reports. In: Stone AA, Turrkan JS, Bachrach CA, Jobe JB, Kurtzman HS, Cain VS (eds) The science of self-report. Implications for research and practice. Lawrence Erlbaum Associates, New Jersey, pp 229-255

- Knappe S, Runge J, Beesdo K, Jacobi F, Wittchen H-U (2008) Diagnosing Mental disorders: gold or Tin Standard. Psychother Psych Med 58:72-75 
- Lachner G, Wittchen H-U (1996) Das Composite International Diagnostic Interview Substance Abuse Module (CIDI-SAM). Ein neues Instrument zur klinischen Forschung und Diagnostik. In: Mann K, Buchkremer G (eds) Sucht. Grundlagen, Diagnostik, Therapie. Gustav Fischer Verlag, Stuttgart, pp 147-156

- Lachner G, Wittchen H-U, Perkonigg A, Holly A, Schuster P, Wunderlich U, Türk D, Garczynski E, Pfister H (1988) Structure, content and reliability of the MunichComposite International Diagnostic Interview (M-CIDI) substance use sections. Eur Addict Res 4:28-41

- Lépine J-P, Wittchen H-U, Essau CA (1993) Lifetime and current comorbidity of anxiety and depressive disorders: results from the international WHO/ADAMHA CIDI field trials. Int J Methods Psychiatr Res 3:67-77

- Lewinsohn PM, Rohde P, Seeley JR (1998) Major depressive disorder in older adolescents: prevalence, risk factors, and clinical implications. Clin Psychol Rev 18:765-794

- Lieb R, Isensee B, von Sydow K, Wittchen H-U (2000) The Early Developmental Stages of Psychopathology Study (EDSP): a methodological update. Eur Addict Res 6:170-182

- Lord C, Rieder A, Hall G, Soares C, Steiner M (2008) Perinatal ObsessiveCompulsive Scale (POCS): preliminary data. Eur Neuropsychopharm 18(suppl.4):S500

- Martini J, Steiner M, Siegert J, Soltau C, Wittchen H-U (2007a) German Version of the Composite International Diagnostic Interview for women (CIDI-V). Institute of Clinical Psychology and Psychotherapy, TU Dresden, Dresden

- Martini J, Steiner M, Siegert J, Soltau C, Wittchen H-U (2007b) German Version of the Composite International Diagnostic Interview for women (CIDI-V): respondent booklet. Institute of Clinical Psychology and Psychotherapy, TU Dresden, Dresden

- Reed V, Gander F, Pfister H, Steiger A, Sonntag H, Trenkwalder C, Sonntag A, Hundt W, Wittchen H-U (1998) To what degree the Composite International Diagnostic Interview (CIDI) correctly identify DSM-IV disorders? Testing validity issues in a clinical sample. Int J Methods Psychiatr Res 7:142-155

- Regier DA (2007) Dimensional approaches to psychiatric classification: refining the research agenda for DSM-V: an introduction. Int J Methods in Psychiatr Res 16:S1S5

- Rieder AD, Soares CN, Lord C, Wittchen H-U, Martini J, Steiner M (2009) Validation of the Composite International Diagnostic Interview - for women (CIDI-VENUS) in a perinatal psychiatric population. Biol Psychiatry 65(suppl)128S

- Rief W, Hessel A, Brähler E (2001) Somatization symptoms and hypochondriacal features in the general population. Psychosom Med 63:595-602

- Robins LN, Helzer JE, Croughan JL, Ratcliff KS (1981) National institute of mental health diagnostic interview schedule: its history, characteristics and validity. Arch Gen Psychiatry 38:381-389

- Robins JN, Wing J, Wittchen H-U, Helzer JE, Babor TF, Burke J, Farmer A, Jablenski A, Pickens R, Regier DA, Sartorius N, Towle LH (1988) The composite international diagnostic interview. An epidemiologic instrument suitable for the use in conjunction with different diagnostic systems and in different cultures. Arch Gen Psychiatry 45:1069-1077

- Rubio-Stipec M, Canino GJ, Robins LN, Wittchen H-U, Sartorius N, Torres de Miranda C (1993) The somatization schedule of the composite international diagnostic interview: the use of the probe chart in 17 different countries. Int J Methods Psychiatr Res 3:129-136 
- Semler G, Wittchen H-U, Joschke K, Zaudig M, von Geiso T, Kaiser S, von Cranach M, Pfister H (1987) Test-retest reliability of a Standardized Psychiatric Interview (DIS/CIDI). Eur Arch Psychiatr Neurol Sci 236:214-222

- Sheehan DV, Lecrubier Y, Harnett-Sheehan K, Amorim P, Janavs J, Weiller E, Hergueta T, Baker R, Dunbar G (1998) The MINI International Neuropsychiatric Interview (M.I.N.I.). The development and validation of a structured diagnostic psychiatric interview for DSM-IV and ICD-10. J Clin Psychiatry 59:S22-S33

- Shear MK, Bjelland I, Beesdo K, Gloster AT, Wittchen H-U (2007) Supplementary dimensional assessment in anxiety disorders. Int J Methods in Psychiatr Res 16:S52S64

- Soares CN, Zitek B (2008) Reproductive hormone sensitivity and risk for depression across the female life cycle: a continuum of vulnerability? J Psychiatry Neurosci 33:331-343

- Spengler P, Wittchen H-U (1988) Procedural validity of standardized symptom questions for the assessment of psychotic symptoms - a comparison of the DIS with two clinical methods. Compr Psychiatry 29:309-322

- Spitzer RL, Williams JBW, Gibbon M, First MB (1992) The Structured Clinical Interview for DSM-III-R (SCID) 1: history, rationale, and description. Arch Gen Psychiatry 49:624-629

- Steiner M, Dunn E, Born L (2003a) Hormones and mood: from menarche to menopause and beyond. J Affect Disord 74:67-83

- Steiner M, Macdougall M, Brown E (2003b) The Premenstrual Symptoms Screening Tool (PSST) for clinicians. Arch Womens Ment Health 6:203-209

- Steiner M, Martini J, Soltau C, Siegert J, Rieder A, Soares C, Wittchen H-U (2007a) Composite International Diagnostic Interview for women (CIDI-V). Institute of Clinical Psychology and Psychotherapy, TU Dresden, Dresden

- Steiner M, Martini J, Soltau C, Siegert J, Rieder A, Soares C, Wittchen H-U (2007b) Composite International Diagnostic Interview for women (CIDI-V): respondent booklet. Institute of Clinical Psychology and Psychotherapy, TU Dresden, Dresden

- Steiner M, Rieder A, Soares CN, Martini J, Wittchen H-U (2008) The Composite International Diagnostic Interview - for women (CIDI-VENUS): a pilot study. Int J Neuropsychopharmacol 11:S311

- van Engeland H, Buitelaar JK (2008) Autism spectrum disorders. In: Ruter M, Bishop D, Pine D, Scott S, Stevenson J, Taylor E, Thapar A (eds) Rutter's child and adolescent psychiatry, 5th edn. Blackwell, Massachusetts, pp 759-781

- van Gülick-Bailer M, Maurer K, Häfner H (1995) Schedules for Clinical Assessment in Neuropsychiatry (SCAN). Huber, Bern

- Williams JB, Gibbon M, First MB, Spitzer RL, Davies M, Borus J, Howes J, Kane J, Pope HG, Rounsaville B, Wittchen H-U (1992) The structured clinical interview for DSM-III-R (SCID).II.Multisite test-retest-reliability. Arch Gen Psychiatry 49:630-636

- Wing JK, Cooper JE, Sartorius N (1974) Measurement and classification of psychiatric symptoms. Cambridge University Press, Cambridge

- Wittchen HU (1993) Computer scoring of CIDI diagnoses. Int J Methods Psychiatr Res 3:101-107

- Wittchen H-U (1994) Reliability and validity studies of the WHO-Composite International Diagnostic Interview (CIDI): a critical review. J Psychiat Res 28:57-84

- Wittchen H-U, Jacobi F (2005) Size and burden of mental disorders in Europe-a critical review and appraisal of 27 studies. Eur Neuropsychopharmacalogy 15:357376 
- Wittchen H-U, Nelson CB (1996) The Composite International Diagnostic Interview: an instrument for measuring mental health outcome? In: Thornicroft G, Tansella M (eds) Mental health outcome measures. Springer, Heidelberg, pp 179-187

- Wittchen H-U, Pfister H (1997) Instruktionsmanual zur Durchführung von DIA-XInterviews. Swets Test Services, Frankfurt

- Wittchen H-U, Pfister H (2004) DIA-X/M-CIDI. DIA-X/CIDI-Composite international diagnostic interview. In: Strauß B, Schumacher J (eds) Klinische Interviews und Ratingskalen. Hogrefe, Göttingen

- Wittchen H-U, Semler G (1990) Composite International Diagnostic Interview (CIDI, Version 1.0). Beltz Verlag, Weinheim

- Wittchen H-U, Burke JD, Semler G, Pfister H, von Cranach M, Zaudig M (1989) Recall and dating of psychiatric symptoms - test-retest reliability of time related symptom questions in a standardized psychiatric interview (CIDI/DIS).ArchGen Psychiatry 46:437-443

- Wittchen H-U, Robins LN, Cottler L, Sartorius N, Burke J, Regier D (1991) Crosscultural feasibility, reliability and sources of variance of the Composite International Diagnostic Interview (CIDI). Br J Psychiatry 159:645-653

- Wittchen H-U, Kessler RC, Zhao S, Abelson J (1995) Reliability and clinical validity of UM-CIDI DSM-III-R generalized anxiety disorder. J Psychiat Res 29:95-110

- Wittchen H-U, Zhao S, Abelson JM, Abelson JL, Kessler RC (1996) Reliability and procedural validity of UM-CIDI DSM-III-R phobic disorders. Psychol Med 26:11691177

- Wittchen H-U, Lachner G, Wunderlich U, Pfister H (1998) Test-retest reliability of the computerized DSM-IV version of the Munich-Composite International Diagnostic Interview (M-CIDI). Soc Psychiatry Psychiatr Epidemiol 33:568-578

- Wittchen HU, Üstün TB, Kessler RC (1999) Diagnosing mental disorders in the community. A difference that matters? Editorial. Psychol Med 29:1021-1027

- Wittchen H-U, Kessler RC, Üstün TB (2001) Properties of the Composite International Diagnostic Interview (CIDI) for measuring mental health outcome. In: Tansella M, Thornicroft G (eds) Mental health outcome measures, 2nd edn. Gaskell, London, pp 212-227

- Wittchen H-U, Becker E, Lieb R, Krause P (2002) Prevalence, incidence and stability of premestrual dysphoric disorder in the community. Psychol Med 32:119-132

- World Health Organization (WHO) (1993) Thenth Revision of the International Classification of Diseases. Chapter V (F). Mental and Behavioral Disorders. Clinical descriptions and diagnostic guidelines. World Health Organization, Geneva

- Yonkers KA, McCunn KL (2007) Comorbidity of Premenstrual Syndrome and Premenstrual Dysphoric Disorder with other psychiatric conditions. In O'Brien PMS, Rapkin AJ, Schmidt PJ (eds.) The Premenstrual Disorders: PMS and PMDD. CRC, pp. 49-54 